\title{
Primer registro de infestación de Piscinoodinium pillulare (Dinoflagellida) en juveniles de Colossoma macropomum (Characiformes: Serrasalmidae) en cultivo semi-intensivo en Loreto, Perú
}

\author{
First record of Piscinoodinium pillulare (Dinoglagellida) infestation in \\ juveniles of Colossoma macropomum (Characiformes: Serrasalmidae) \\ in semi-intensive fish farming in Loreto, Peru
}

\author{
Humberto Arbildo-Ortiz ${ }^{1,2,5}$, Juleysi Alvez-Robledo ${ }^{1}$, Carlos Chuquipiondo \\ Guardia $^{1,2}$, Amanda Karen Silva de Souza ${ }^{3,4}$
}

\section{Resumen}

\begin{abstract}
El objetivo del estudio fue describir un caso de infestación de Piscinoodinium pillulare y mortalidad en juveniles de Colossoma macropomum. En marzo de 2019, ante una creciente ocurrencia de mortalidad en los peces de un estanque de tierra, se colectaron 21 ejemplares juveniles de un cultivo en la zona de Maynas, Loreto (Perú). Se realizó el análisis parasitológico de las partes externas de los peces y se observó la presencia de P. pillulare localizados en la piel, aletas, branquias y fosas nasales. Asimismo, se registró una mortalidad de 30\% (1500 de 5000 sembrados). La no desinfección del estanque, el inadecuado control en la alimentación, y la proliferación de Oreochromis niloticus (tilapia) en el cultivo fueron los causantes de la proliferación de $P$. pillulare. Este es el primer caso reportado de infestación de $P$. pillulare en juveniles de $C$. macropomum cultivados en la Amazonia Peruana.
\end{abstract}

Palabras clave: Colossoma macropomum, Piscinoodinium pillulare, cultivo, granja piscícola, Perú

\footnotetext{
${ }^{1}$ Universidad Nacional de la Amazonia Peruana, Programa de Maestría en Acuicultura, Loreto, Perú

${ }^{2}$ Amazon Research Center for Ornamental Fishes, Iquitos, Perú

${ }^{3}$ Laboratorio de Parasitología de Peixes, Instituto Nacional de Pesquisas da Amazonia - INPA, Manaus, Amazonas, Brasil

${ }^{4}$ Laboratório de Biologia Celular e Helmintologia da Universidade Federa do Pará, Belém, Brasil

${ }^{5}$ E-mail:doc.arbil@gmail.com
} 
The aim of this study was to describe a case of Piscinoodinium pillulare infestation and mortality in juveniles of Colossoma macropomum. In March 2019, 21 juvenile specimens of a semi-intensive fish farm were collected in the Maynas area, Loreto (Peru). Parasitological analysis of the external parts of the fish was performed and the presence of $P$. pillulare located on the skin, fins, gills, and nostrils was observed. Furthermore, a $30 \%$ mortality was recorded ( 1500 out of 5000 seeded). The non-disinfection of the pond, the inadequate control in the feeding, and the proliferation of Oreochromis niloticus (tilapia) in the culture were the causes of the proliferation of $P$. pillulare. This is the first reported case of $P$. pillulare infestation in juveniles of $C$. macropomum grown in the Peruvian Amazon.

Key words: Colossoma macropomum, Piscinoodinium pillulare, culture, fish farm, Perú

\section{INTRODUCCIÓN}

Colossoma macropomum (Cuvier, 1816) es una especie de pez de hábitos alimenticios omnívoro, que en las etapas de larvas y juveniles se alimentan de zooplancton. Esta especie se encuentra distribuida en Perú, Colombia, Bolivia, Brasil, Venezuela y Ecuador. En ambientes naturales pesa $30 \mathrm{~kg}$ como máximo y mide $100 \mathrm{~cm}$, mientras que en cultivo en ambientes controlados en el Perú puede llegar a pesar hasta más de $1 \mathrm{~kg}$ a los 8-12 meses (Eufracio y Palomino, 2004; Santos et al., 2006; García-Dávila et al., 2018).

El principal productor de C. macropomum es Brasil. Su cultivo en el Perú se ha incrementado de $414 \mathrm{t}$ en 2007 a $1986 \mathrm{t}$ en 2016, cultivándose en las regiones Loreto, Madre de Dios, Ucayali y San Martín, siendo la Región Loreto el principal productor (Valladão et al., 2016; PRODUCE, 2017).

Piscinoodinium pillulare (Schäperclaus 1954, Lom, 1981) es un mastigóforo registrado en pisciculturas tropicales y de regiones templadas. No tiene especificidad parasitaria y en los peces se localiza en piel, branquias y epitelio bucal y nasal. Causa irritación, hemorragias, petequias en el tegumento, degeneración y degeneración de las célu- las y ligeras inflamaciones. Peces con elevada intensidad de infestación tienen una apariencia aterciopelada, llegando a morir o disminuir su crecimiento (Eslava y Iregui, 2000; Verján et al., 2001; de Fogel et al., 2004; Junior et al., 2018; Morey, 2019).

A pesar de la importancia económica de $C$. macropomum para la piscicultura en Perú, no se conoce de casos de infestaciones por parásitos protozoarios en cultivo. En este contexto, el presente trabajo tuvo como objetivo describir un caso de infestación de $P$. pillulare y mortalidad de juveniles de $C$. macropomum criados en cultivo semi-intensivo en la Amazonia Peruana.

\section{Materiales y Métodos}

El muestreo de los peces se realizó en un fundo de la Carretera Iquitos-Nauta (en las coordenadas $4^{\circ} 11^{\prime} 15^{\prime \prime} \mathrm{S}$ y $73^{\circ} 28^{\prime} 35^{\prime \prime} \mathrm{O}$ ), del distrito de San Juan Bautista, provincia de Maynas, Región Loreto (Perú).

En setiembre de 2018, 5000 alevinos de C. macropomum de peso $2.5 \pm 0.1 \mathrm{~g}$ y longitud de $3.0 \pm 0.3 \mathrm{~cm}$, producidos mediante reproducción artificial, fueron sembrados en dos jaulas de $20 \mathrm{~m}^{2}$ en un estanque de tierra 


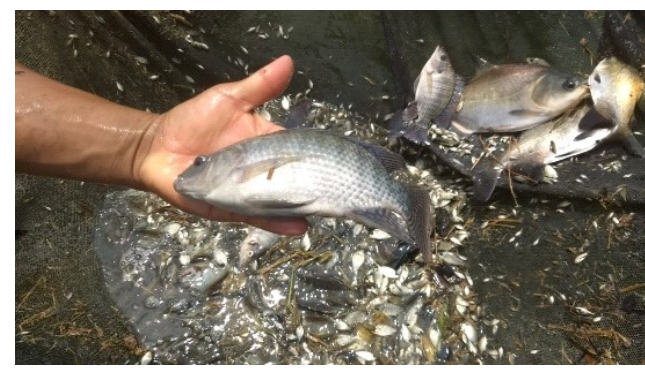

Figura 1. Especímenes de Oreochromis niloticus (tilapia) en diferentes estadios, capturados en un estanque de cultivo de Colossoma macropomum (Loreto, Perú)
(2003). Se hicieron raspados con una espátula en la superficie del cuerpo, aletas y branquias, las muestras fueron puesta en portaobjeto y cubiertas con laminillas para su observación al microscopio compuesto (Nikon E2000 Eclipse). Algunas muestras fueron fijadas en alcohol de $70^{\circ}$. La identificación de los parásitos fue de acuerdo con Lom y Dykova (1992).

Los parámetros de calidad de agua, temperaturas $\left({ }^{\circ} \mathrm{C}\right)$, oxígeno disuelto, $\mathrm{pH}(\mathrm{UI})$, dióxido de carbono (ml/l) y amonio ( $\mathrm{ml} / \mathrm{l})$ fueron analizados al momento de la colecta de los especímenes (09:00 h), mediante un kit limnológico de agua dulce (LaMotte AQ-2).

\section{Resultados}

ses, recibiendo alimento balanceado extruido inicio $28 \%$ de proteína bruta-PB (Aquatech), dos veces al día. Los peces fueron liberados de las jaulas al tercer mes en el mismo estanque, a una densidad de $1 \mathrm{pez} / \mathrm{m}^{2}$, recibiendo alimento balanceado extruido crecimiento $25 \%$ PB (Aquatech), con una frecuencia de dos veces al día. El abastecimiento de agua al estanque procedía de escorrentía y de un estanque donde se venía cultivando tilapias (Oreochromis niloticus, Linnaeus 1758)

A inicio de marzo de 2019 se observó la muerte de gran cantidad de peces, llegándose a registrar una mortalidad de 30\% (1500 especímenes). Por otro lado, se observó en el estanque de cultivo la presencia abundante de $O$. niloticus, en los estadios de alevinos, juveniles, adultos y reproductores (Figura 1).

En marzo de 2019 se evaluaron $21 \mathrm{ju}$ veniles de $C$. macropomum, de $434.1 \pm 151.8$ g y $29.1 \pm 3.3 \mathrm{~cm}$ de longitud total. Los peces fueron seleccionados al azar, toda vez que todos presentaban signos de parasitosis. Los peces fueron transportados en bolsas plásticas y trasladadas al laboratorio de la $\mathrm{ONG}$ Amazon Research Center for Ornamental Fishes, ubicado en Iquitos, Perú. La necropsia fue realizada de acuerdo con Eiras et al.
En la necropsia de los peces, la superficie de la piel presentaba un color marrón a verde, y en algunos especímenes se observó necrosis en la piel y petequias (Figuras 2, 3). Los peces tenían abundante presencia de $P$. pillulare, los cuales se encontraban ubicados en la piel, aletas, branquias y fosas nasales.

\section{Discusión}

En la acuicultura de especies nativas América del Sur se han registrado enfermedades producidas principalmente por patógenos protozoarios (Ichthyophthirus multifilis), especies de monogeneos y Trichodinas, bacterias (Aeromonas hydrophila), copépodos (Perulernaea 


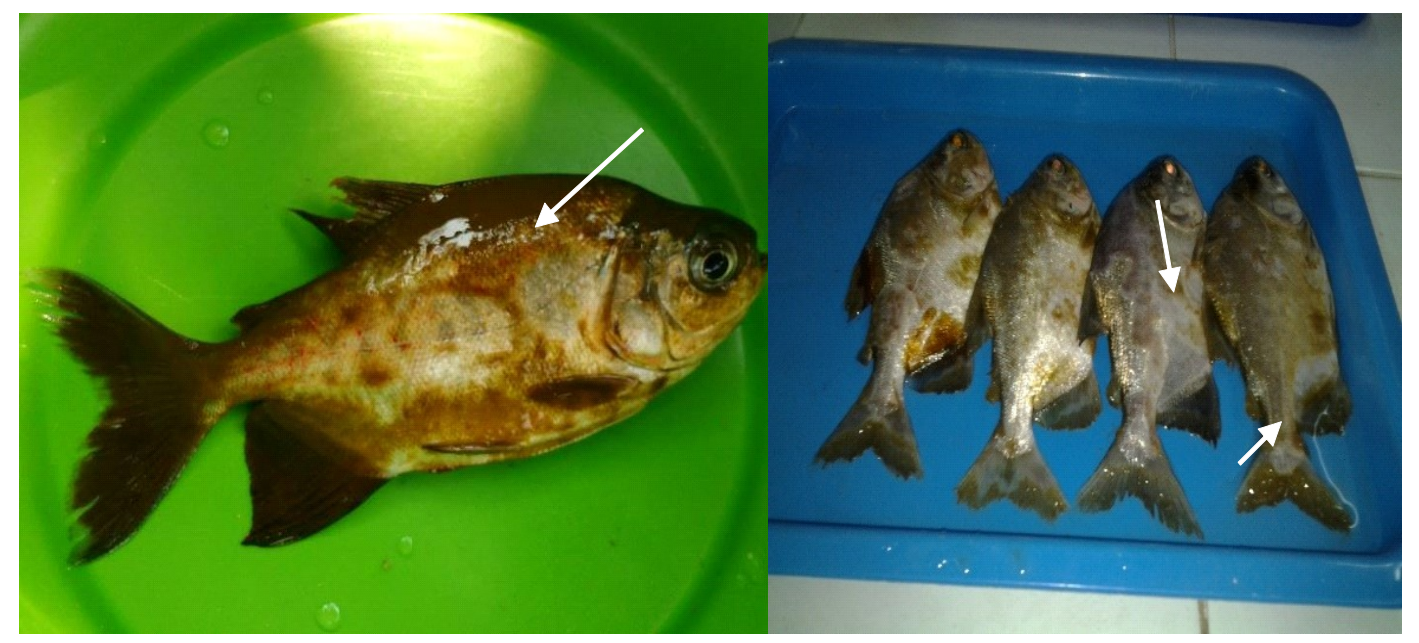

Figura 2. Espécimen de Colossoma macropomum (izquierdo) con presencia de Piscinoodinium pillulare en superficies del cuerpo y especímenes de C. macropomum con necrosis y desprendimiento de escamas (derecho)

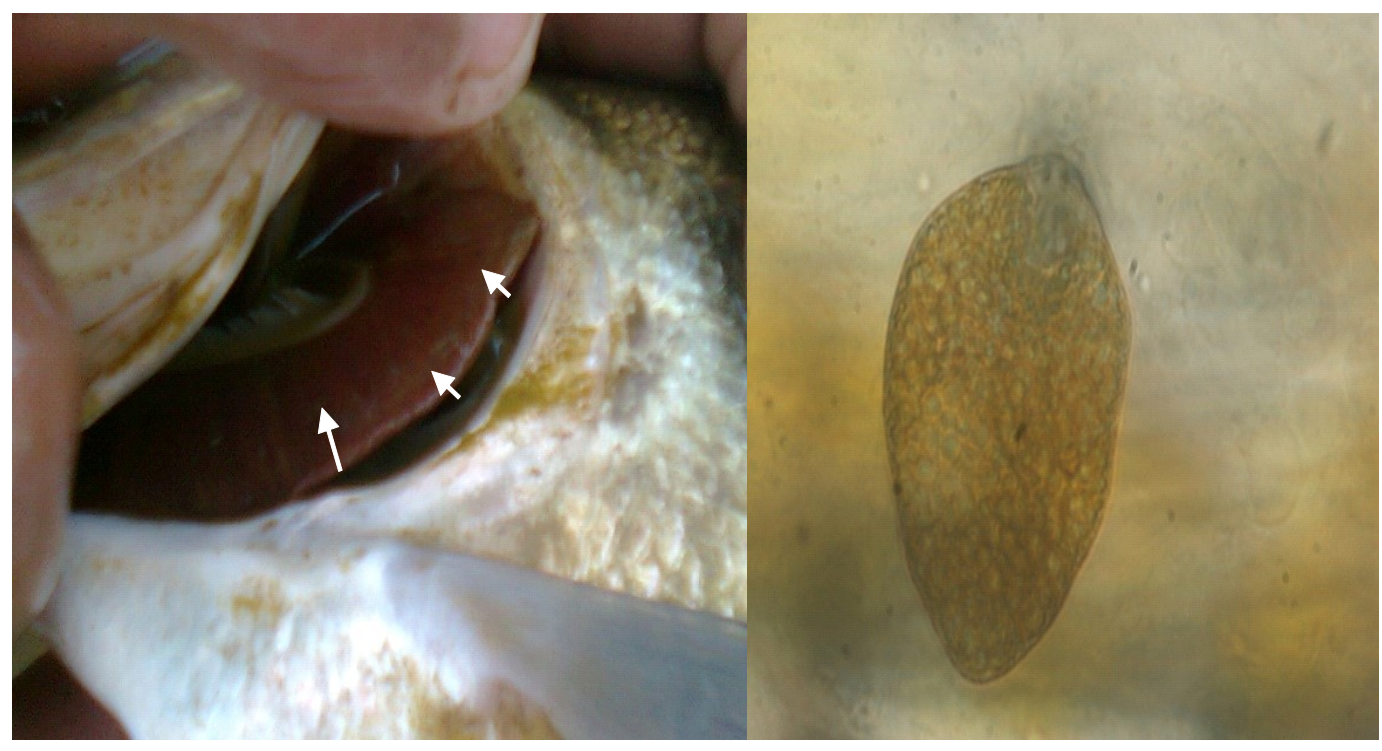

Figura 3. Branquia de Colossoma macropomum con abundante presencia de trofontes de Piscinoodinium pillulare y trofonte de espécimen de $P$. pillulare adherido a la piel 
gamitanae) y nematodos (Goezia spinulosa) (Valladão et al., 2016). En el Perú, en el cultivo de Colossoma macropomum se han registrado dos casos de infestación producidas por $P$. gamitanae que cursaron con mortalidad de los peces (Mathews et al., 2011; Arbildo-Ortiz et al., 2019). Asimismo, se ha registrado la presencia frecuente de parásitos monogeneos en los cultivos (Bances et al., 2013; Soberón et al., 2014; Cayulla, 2018).

Según la literatura, $P$. pillulare es un parásito no específico y frecuente en el cultivo de C. macropomum. En este trabajo se encontró una elevada infestación en piel, aletas, branquias y fosas nasales, coincidiendo en estas zonas corporales con reportes de otros autores (Martins et al., 2001; Verján et al., 2001; Sant'Ana et al., 2012; Junior et al., 2018). Los resultados indican que este es el primer registro en Perú de infestación de $P$. pillulare en $C$. macropomum, con una mortalidad de 30\% (1500 especímenes), Casos similares de infestaciones han sido registrados en Brasil (Martins et al., 2001; Sant'Ana et al., 2012; Junior et al., 2018) y Colombia (Verján et al., 2001). La alta infestación de $P$. pillulare en este estudio pudo deberse al estrés que sufrieron los peces, por la falta de desinfección del estanque al momento de la siembra, por el inadecuado control en la ración del alimento suministrado a los peces y por la elevada densidad de siembra de los peces, esta última exacerbada por la proliferación de $O$. niloticus, las cuales ingresaron a través del desagüe.

Sant'Ana et al. (2012) registraron tres casos de infestaciones de P. pillulare en cultivo intensivo de Piaractus mesopotamicus (Holmberg, 1887) en el Sureste de Goiás, con mortalidades entre 59 y $90 \%$, en tanto que Junior et al. (2018) registraron $1.2 \%$ de mortalidad en un policultivo de Colossoma macropomum, Piaractus brachypomus y $O$. niloticus en la ciudad de Gama, Brasil. La diferencia en las tasas de mortalidades se debería al manejo en el cultivo. Por otro lado, en Colombia, Verján et al. (2001), al evaluar brotes de enfermedades en el cultivo de Piaractus brachypomus durante 18 meses, indicaron que el $33 \%$ de los casos fueron producidos por el dinoflagelado Piscinoodinium sp.

El elevado costo del alimento balanceado en el cultivo de Arapaima gigas (Schinz,1822) paiche, ha ocasionado que algunos piscicultores de la zona del estudio cultiven $O$. niloticus (tilapia) de manera ilegal, traídas del departamento de San Martín, para ser utilizada como peces forraje para el engorde de paiche; sin embargo, no se ha tenido en cuenta los daños que puede ocasionar al ingresar y proliferar en otros estanques de cultivos, como es el caso de C. macropomum. El cultivo de $O$. niloticus está prohibido en la cuenca Amazónica Peruana (PRODUCE, 2006), a excepción de los departamentos de Amazonas, Cajamarca, Huánuco, Junín y San Martín (PRODUCE, 2019).

En esta investigación, cuando los peces comenzaron a morir, se disminuyó la densidad de siembra, trasladando 500 especímenes a otro estanque, se suspendió la alimentación por tres días, se bajó el nivel del agua a $1 \mathrm{~m}$ de profundidad y se adicionó cloruro de sodio $\left(25 \mathrm{~g} / \mathrm{m}^{2}\right)$ por tres días. Al cuarto día de haber suspendido la alimentación se suministró alimento balanceado engorde de $45 \%$ de PB mezclado con metronidazol (2 pastilla de metronidazol de $500 \mathrm{mg} / 25 \mathrm{~kg}$ de alimento) durante una semana. Este tratamiento disminuyó la mortalidad y eliminó el $P$. pillulare de los juveniles de C. macropomum. Asimismo, con una red de pesca se retiraron más de 10500 tilapias de diferentes estadios.

En el control de la infestación de $P$. pillulare, Pavanelli et al. (1999) utilizaron baños de formalina a una concentración de 150 a $300 \mathrm{ml} / \mathrm{m}^{3}$ durante $30-35$ minutos; Claudiano et al. (2009) reporta el uso del extracto acuoso de hojas secas de Terminalia catappa $(120 \mathrm{ml} / \mathrm{l})$, mientras que Ferreira et al. (2019) en peces juveniles de $C$. macropomum infestados experimentalmente por P. pillulare evaluó la eficacia del aceite Menth a piperita, con variados resultados. 
La presencia de $P$. pillulare en una especie de importancia comercial en la acuicultura amazónica como es C. macropomum debe poner en alerta a las autoridades sanitarias del Perú; asimismo se deben realizar monitoreos ictiparasitologicos constantes en los centros piscícolas del eje de la carretera Iquitos-Nauta y seguir investigando sobre la presencia y control de $P$. pillulare.

\section{Literatura Citada}

1. Arbildo-Ortiz, H, Alvez-Robledo J, Silva de Souza AK. 2019. Perulernaea gamitanae (Crustacea: Lerneaidae) en juveniles de Colossoma macropomum (Characiformes: Sarrasalmidae) en cultivo semi-intensivo en Loreto, Perú. Rev Inv Vet Perú 30: 350-356. doi: 10.15381/ rivep.v30i1.14726

2. Bances KC, Arbildo H, Ruiz, A. 2013. Índices parasitarios en larvas, poslarvas y alevinos de Colossoma macropomum (gamitana) en estanques del Instituto de Investigaciones de la Amazonía Peruana. Conocimiento Amazónico 4: 107-113.

3. Cayulla D. 2018. Identificación de monogeneos en juveniles de Colossoma macropomum «gamitana» y Piaractus brachypomus «paco» procedentes del distrito de Tambopata, Madre de Dios. Tesis de Biólogo. Lima: Univ. Nacional Mayor de San Marcos. 84 p.

4. Claudiano GDS, Diaz Neto J, Sakabe R, Cruz C, Salvador R, Pilarski F. 2009. Eficácia do extrato aquoso de Terminalia catappa em juvenis de tambaqui parasitados por monogenéticos e protozoários. Rev Bras Saúde Prod An 10:625-636.

5. De Fogel FDE, Fuentes ZJL, Gonzales I. 2004. Parasitosis en Colossoma macropomum (Pisces: Characidae) cultivado, ocasionada por los protozoos Ichthyophthirius multifilis (Fouquet) y Piscinoodinium pillulare (Schaperclaus). Agrobiología 16: 3-8.
6. Eiras JC, Takemoto RM, Pavanelli $G C$. 2003. Método de estudio y técnica laboratoriales en parasitología de peces. Zaragoza, España: Acribia. 142 p.

7. Eufracio P, Palomino A. 2004. Manual de cultivo de gamitana - Programa de Transferencia de Tecnología en Acuicultura para Pescadores Artesanales y Comunidades Campesinas. AECI/ PADESPA-FONDEPES. [Internet]. Disponible en: http://www2.produce.gob.pe/RepositorioAPS/3/jer/ ACUISUBMENU 4/manua _ - $_{\text {- }}$ gamitana.pdf

8. Eslava PR, Iregui CA. 2000. Estudios sobre enfermedades branquiales de la cachama blanca (Piaractus brachypomus). Orinoquia 4: 123-115.

9. Ferreira LC, da Cruz MG, Lima TBC, Serra BNV, Chaves FCM, Chagas EC, Ventura AS, et al. 2019. Antiparasitic activity of Mentha piperita (Lamiaceae) essential oil against Piscinoodinium pillulare and its physiological effects on Colossoma macropomum (Cuvier, 1818). Aquaculture 512: 734343. doi: 10.1016/ j.aquaculture.2019.734343

10. García-Dávila C, Sánchez H, Flores M, Mejia J, Angulo C. Castro-Ruiz D, Estivals G, et al. 2018. Peces de consumo de la Amazonía peruana. Iquitos, Perú: Instituto de Investigaciones de la Amazonía Peruana (IIAP). 218 p.

11. Junior JAF, Leonardo AS, Azevedo JPMVB, Rodrigues FR, Nascimento KA, Macêdo JTSA, Pedroso PMO. 2018. Outbreak of infection by Piscinoodinium pillulare and Trichodina spp in tambaquis (Colossoma macropomum), pirapitingas (Piaractus brachypomus) and tilapias (Oreochromis niloticus) in the Federal District, Brazil. Acta Sci Vet 46(Suppl 1): 293. doi: 10.22456/1679-9216.86827

12. Lom J, Dykova I. 1992. Protozoan parasites of fishes. Developments in aquaculture and fisheries science. Amsterdam: Elsevier. 315 p. 
13. Mathews PD, Mathews DJP, Arenas $J$, Orbe R. 2011. Massive infestation by Perulernaea gamitanae (Crustacea: Cyclopoida: Lernaidae) in juvenile gamitana, cultured in the Peruvian Amazon. Vet México 42: 59-64.

14. Martins ML, Moraes JRE, Andrade PM, Schalch SHC, Moraes FR. 2001. Piscinoodinium pillulare (Schäperclaus, 1954) Lom, 1981 (Dinoflagellida) infection in cultivated freshwater fish from the northeast region of São Paulo State, Brazil: parasitological and pathological aspects. Braz J Biol 61: 639-644. doi: 10.1590/s1519-69842001000-400013

15. Morey GAM. 2019. Parasitología en peces de la Amazonía. Fundamentos y técnicas parasitológicas, proûlaxis, diagnóstico y tratamiento. Iquitos, Perú: Instituto de Investigaciones de la Amazonía Peruana (IIAP). $100 \mathrm{p}$.

16. Pavanelli GC, Eiras JC, Takemoto RM. 1999. Doenças de peixes. Profilaxia, diagnóstico e tratamento. Maringá, Brasil: Univ. Estadual de Maringá. $264 \mathrm{p}$.

17. [PRODUCE] Ministerio de la Producción. 2016. Decreto Supremo $N^{\circ} 011-$ 2016-Produce. [Internet]. Disponible en: http://extwprlegs1.fao.org/docs/pdf/ per63919.pdf

18. [PRODUCE] Ministerio de la Producción. 2017. Anuario Estadística pesquero y acuícola 2016. [Internet]. Disponible en: http://ogeiee.produce.gob.pe/index.php/ shortcode/oee-documentos-ublicaciones/ publicaciones-anuales/item/775-anuarioestadistico-pesquero-y-acuicola-2016
19. [PRODUCE] Ministerio de la Producción. 2019. Decreto Supremo $N^{\circ} 040$ 2019-Produce. [Internet]. Disponible en: https://cdn.www.gob.pe/uploads/ document/file/293471/Resoluci\%C3\%B3n_Ministerial_N_040-2019PRODUCE_101676_1_201-9022119080-1g5kuk1.pdf

20. Santos GM, Ferreira EJG, Zuanon JA S. 2006. Peixes comerciais de Manaus. Manaus, Amazonas: Instituto Nacional de Pesquisas da Amazônia. 141 p.

21. Sant'Ana FJF, Oliveira SL, Rabelo RE, Vulcani VAS, Silva SMG, Ferreira JA. 2012. Surtos de infecção por Piscinoodinium pillulare e Henneguya spp. em pacus (Piaractus mesopotamicus) criados intensivamente no $\mathrm{Su}-$ doeste de Goiás. Pesqui Vet Bras 32: 121-125. doi: 10.1590/S0100-736X2012000200005

22. Soberón L, Mathews P, Malherios A. 2015. Hematological parameters of Colossoma macropomum naturally parasitized by Anacanthorus spathulatus (Monogenea: Dactylogiridae) in fish farm in the Peruvian Amazon. Int Aquat Res 6: 251-255.

23. Valladão GM, Gallani S, Pilarski F. 2016. South American fish for continental aquaculture. Rev Aquac 10: 351-369. doi: 10.1111/raq.12164

24. Verján N, Iregui C, Rey A, Eslava P. 2001. Estudio de brotes de enfermedades en la cachama blanca Piaractus brachypomus: Diagnóstico y caracterización. Rev MVZ Córdoba 48:48-56. 